\title{
Military Work by Space Exploration Organizations: A Barrier to Inclusion and Safe Workspaces for Marginalized Communities
}

A white paper submitted to the Planetary Science and Astrobiology Decadal Survey 2023-2032 as part of a collaborative effort organized by the Equity, Diversity, and Inclusion Working Group (EDIWG), a cross Assessment Group (AG) committee.

Corresponding Author:

Zahra Khan, Independent Researcher, 617-910-0560, zahrak@alum.mit.edu

\section{Co-authors:}

Erika Nesvold, The JustSpace Alliance; Rebecca Smith, Stony Brook University; Sarah Swiersz, University of Central Florida; Lucianne M. Walkowicz, The JustSpace Alliance

\section{Project Website: https://spacesciencemic.wordpress.com/}

\section{Endorsements by Date of Submission (updates at project website):}

Timothy A. Goudge, The University of Texas at Austin; Michaela Leung, University of California-Riverside; Christina Richey, Jet Propulsion Laboratory, California Institute of Technology; Michael W. Busch, SETI Institute; Divya M. Persaud, University College London; Moses Milazzo, Other Orb LLC; Meredith Durbin, University of Washington; Noel A. Scudder, Purdue University; Antonella Alunni, NASA Ames Research Center; Chanda Prescod-Weinstein, University of New Hampshire; Luna Zagorac, Yale University; Hajar Boughoula, NASA Mission to Psyche; Gourav Khullar, University of Chicago; Sarah Tuttle, University of Washington; Alice Gorman, Flinders University ; Charlotte Minsky, Massachusetts Institute of Technology; Andrés Plazas, Princeton University; David Dubois, NASA Ames Research Center; Serina Diniega, Jet Propulsion Laboratory, California Institute of Technology; Hayley Williamson, IRF; Federica Bianco, University of Delaware; C. Adeene Denton, Purdue University; Meredith Rawls, University of Washington/Rubin Observatory; Damien Patrick Williams, Virginia Polytechnic Institute and State University/The JustSpace Alliance; Benjamin Pope, New York University; Sabine Stanley, Johns Hopkins University; Laura Chaves, Purdue University; Julie Rathbun, Planetary Science Institute; Marshall J. Styczinski, University of Washington; Nicole Whelley, University of Maryland - College Park, NASA Goddard Space Flight Center; Brian Nord, Fermilab/University of Chicago; Alessondra Springmann, University of Arizona; Jamie L. Molaro, Planetary Science Institute; Samuel Jacob Baker, University of Central Florida; Amy LeBleu-DeBartola, University of Central Florida; Romy D. Hanna, University of Texas at Austin; Buraaq Alrawi, University of California - Merced; Kristin M. Block, University of Arizona; Evan L. Sneed, Pennsylvania State University; Ebony D. Johnson, University of Michigan; Michole Washington, STEMulation Escape Room; Anthony J. Abel, University of California Berkeley; Gwen Hanley, University of California - Berkeley; Eleni Ravanis, European Space Agency/University of Hawai'i at Manoa; Nils JH Averesch, Stanford University; Jacob M. Hilzinger, University of California - Berkeley; Rebecca Colby, Massachusetts Institute of Technology 


\subsection{Key Issue and Overview of Impact on the Field}

“...the perspective of space exploration gives us the ability to see Earth and humanity as one, but some of the technology simultaneously threatens to doom our civilization. I have at times felt uncomfortable about working closely with contractors whom I know have also participated in the hardware of death and destruction." - Dr. David Grinspoon

This paper responds to the Planetary Science and Astrobiology Decadal Survey 2023-2032 topic of "The state of the profession including issues of diversity, inclusion, equity, and accessibility, the creation of safe workspaces, and recommended policies and practices to improve the state of the profession". Specifically, the authors seek to broaden the profession's conception of what creating safe workspaces entails beyond issues of interpersonal and structural biases affecting individuals from marginalized groups in terms of hiring, career progression, etc., to also include ethical dilemmas presented by our work itself that may have higher impacts on our colleagues from marginalized communities. For this paper, we focus on the impact of the US space science industry's involvement with the US military-industrial complex (MIC) on marginalized space science workers and students. We are interested in how collaborations between space science labs and labs/companies performing military work affects employee mental health, engagement, and retention.

Space science labs are involved with MIC organizations doing work on technologies such as weapons, surveillance aircraft and spacecraft, and machine learning and artificial intelligence for military use. These organizations not only supply this equipment to our military but are responsible for arms sales around the world [1], supplying military equipment to our domestic police forces and surveillance agencies. While many members of the space science community have positive associations with our military, police, and intelligence agencies, these agencies' extensive history of targeting black, indigenous, and people of color (BIPOC) abroad and at home, though concerning for all, may have a higher negative impact on marginalized members of our profession and, consequently, on their experience working in spaces with ties to these agencies. Additionally, knowledge of these ties may also deter students from pursuing these fields due to ethical concerns.

In this paper, we present an initial analysis of this problem. Our goal is to raise this as an issue of concern to the Planetary Science and Astrobiology community and encourage further study as part of diversity, equity, inclusion and accessibility (DEIA) initiatives.

\subsection{White Paper Methodology}

To study space science community members' perceptions of and concerns about work environments tied to the MIC, we employed the qualitative methodology of Grounded Theory (GT), which consists of collecting data from primary sources to analyze for emergent theories [2]. As no theory exists in the literature about this social phenomenon, employing these qualitative methods is appropriate for building theory and determining if the issue presents problems for further study and hypotheses to test. To collect examples of researchers who have struggled with the influence of the MIC in 
their institutions, we posted a call for stories via a public Google form [3]. The form collected non-identifying demographic information and provided space for the respondent to "Tell us [their] story", and was advertised on Twitter, Facebook, Linkedln, and various email lists beginning on June 9, 2020. In addition to collecting personal stories, we performed a literature review to seek insights from results of social studies in other fields regarding topics such as ethical/moral stress, moral action, job satisfaction, and employee retention.

\subsection{Results and Discussion}

A total of 29 responses to the form were received spanning various education and career levels, ethnicities, genders, religious affiliations and, citizenships. We observed three emergent themes in the responses: (1) the extent of MIC ties to space science job opportunities; (2) effects on recruitment and retention; (3) the impact on mental health.

\subsection{Extent of MIC ties in space science workplaces}

Job opportunities in space science are mostly provided by industry, research laboratories, and academia, and all three workplaces can have ties with the MIC. While many space scientists and engineers who are employed in these types of workspaces do not directly work on military technology, there is often an overlap of funding and expertise between scientific and military research. As one of our respondents described it: "I knew about the military-industrial complex but naively thought it wouldn't have an impact on my career as long as I was only working on planetary missions etc. When it came time to actually find a job, I realized it was difficult to find an aerospace company to work at that didn't also work with the military." Other respondents described finding their research evolving to become more involved with the MIC over time, but feeling afraid to speak up due to the potentially negative career repercussions.

Many aerospace corporations that employ engineers and space scientists are granted large contracts with NASA (e.g., Ball Aerospace, Boeing, Honeywell, Lockheed Martin, Northrop Grumman, and Raytheon) to build space science systems but are also the top US defense contractors [1,4]. These weapons are used both abroad and at home against civilians through a federal program that allows the Department of Defense (DoD) to get rid of excess equipment by passing it off to local police departments.

National and Principal Investigator (PI)-led research laboratories can also have ties to the MIC by either receiving funds from government or industry organizations involved with military work, or by working on research projects with organizations doing military work. For example, Los Alamos National Laboratory is managed by the National Nuclear Security Administration and maintains the national stockpile of nuclear weapons, but also has a space science research program. Additionally, instruments on NASA missions are often built as collaborations between academic institutions and aerospace corporations that conduct MIC-related work. Some academic "enrichment programs," such as the BeaverWorks program at MIT/Lincoln Labs (a DoD-funded lab), provide research opportunities for high school and undergraduate students, further facilitating early involvement of students with MIC-related work [5]. 
Corporations and laboratories are not required to be transparent about their ties with the MIC, and this lack of transparency has caused issues for a number of our respondents. For example, one respondent expressed frustration that after a few months at a position, they learned that the technology they were hired to work on was originally developed by US military for the purpose of war, and that the position required collaboration with US military: "I don't want to use my science training and lab experience to help with any warfighting effort." Another story reported distress after being put on defense-related projects even though they were initially told they would only work on civilian-related projects. These responses highlight the need for transparency. We hypothesize that ties between the MIC and space science are a concern for workers in the space industry, and that involvement of space science with the MIC inhibits career development for those with ethical concerns surrounding MIC entanglement

The extensive overlap between the MIC and the space science field make it so that one's career can be affected by this relationship at any point. It would seem that these relationships in the workplace would mostly affect early-career professionals who are applying to positions at a high rate. However, ethical dilemmas can surface at any point, affecting recruitment and retention in the space science field (section 3.2), and can also affect the mental health of a professional after years at a position (section 3.3).

"... as a postdoc in the space science field, I am having trouble finding positions at organizations that are not involved in MIC work. I had a friend of a friend reach out about a geology/space science position at Lawrence Livermore National Lab, but I declined to apply because the position would require me to do work on national defense issues, which creates an ethical dilemma for me."

\subsection{Recruitment and retention}

Our survey was advertised in online spaces frequented by current space science workers and students, and therefore did not thoroughly survey former workers who have since left these fields, or potential students who chose not to enter the field in the first place. However, we received some responses from these groups suggesting that the space industry's ties to the MIC likely contribute to the lack of diversity within our industry via impacts on recruitment and retention.

A former worker of Iranian descent said: "Two years into working at NASA I started taking Film Theory and Production classes at Rice University. I started reading critical theory, started learning about imperialism and identity for the first time. My attitude towards my job changed as I realized how militarized the space industry was. I came to find out that Lockheed Martin was the biggest arms producer in the world. After that transformative first semester at Rice, it became harder to drag myself out of bed each morning...It took me 3 more years to leave and go to graduate school. The fact that even space was tainted with corporate and imperialist militarization was in fact a main reason I decided to study political philosophy."

Another respondent shared that: "Ethical concerns and generally non-inclusive cultures are the two primary reasons I left the field. ...I felt I was constantly trying to justify my continued work at companies that felt out of line with my ethics - even when the program I worked on did not have military ties, I knew the company as a whole was supported by military funding. I saw a friend pushed out of a company after asking 
management to support her request to not work on military projects (a requirement she had discussed with them prior to her hiring)....For people like myself who are concerned about surveillance, the unending killing of non-white people by the US military around the world, and human rights, there is no reliable way to bring space work in line with these beliefs."

Several respondents also noted that they were considering leaving their field or were struggling to find jobs in their industry that did not violate their personal ethics. One student respondent said: "I'd like to explore other post-academic careers but many would involve defense contractors and I don't want that on my conscience." Others found themselves losing motivation to continue advancing their careers. As one midcareer scientist reported: "When I graduated I pictured myself climbing the ranks, becoming an executive, and being important and groundbreaking in my field. That has drastically changed after seeing the full scope of the military industrial complex."

The majority of civilian victims of the US MIC in recent decades have been in the Middle East (ME). For industry workers of ME descent, the ethical dilemma of working with the MIC can be especially salient. As a student respondent "of Middle Eastern heritage" noted: "I really don't like having to weigh my astronomical adjacency to the US military industrial complex against my background and the safety of people who look like me." These anecdotal reports suggest that industry workers from groups that have been particularly targeted by the US MIC may have a higher incentive to leave or avoid fields that overlap with MIC work, contributing to decreased diversity in space science. Some respondents also expressed concerns that increased militarization of space work decreases job opportunities for non-US citizens due to national security rules such as ITAR.

In the US, BIPOC have experienced racial injustice at the hands of heavily militarized police forces and the military itself [6]. These interactions could negatively impact how people with these identities view space science once they learn about ties with the MIC. A 2016 study by the University of Chicago found that black and female adults are less likely to report a "great deal" of confidence in scientists than white male adults [7]. In a report by the American Academy of Arts \& Sciences it was hypothesized that some of this gap could be related to cultural differences such as the [negative] historical relationship between science and race [8], and this hypothesis could carry over to the space sciences, especially with the ties to military work.

\subsection{Impact on mental health}

Space science links to the MIC also have a detrimental impact on the mental health and job satisfaction of people who remain in the field. Several respondents noted that the moral dilemma they feel due to their work's proximity to the MIC has negatively affected their mental health. One early-career respondent reported that their ethical concerns about their work being used by the MIC have only grown since the start of their career: "My internal conflict is becoming harder to ignore. This has affected my mental wellbeing and engagement at work." Another respondent said: "[l] quickly became disillusioned as I learned that the technology used to produce the instruments [developed by my PI for space exploration missions] came from military research and development, and was built in part by aerospace industry corporations also involved with MIC work (Raytheon). This connection deeply troubled me, and was part of what 
caused me to be dissatisfied with my choice for field of study, leading to years of depression."

In general, mental health problems are very common in working populations, and there are demonstrated links between psychosocial working conditions-or job stressors-and worker health [9]. For example, one study showed that $45 \%$ of incident cases of depression and anxiety in previously healthy young workers were attributable to job stress [10]. In addition to depression, job stressors have been associated with burnout, anxiety disorders, alcohol dependence, suicide and other mental health outcomes [11,12]. Such job stressors can include ethical/moral stress, a painful feeling and/or psychological disequilibrium that occurs when a person is tasked with actions different from what they think is the right action, or are unable to take morally appropriate action because of institutional obstacles [13]. A study on the predictors of ethical stress, moral action and job satisfaction in health care social workers found that higher levels of ethical stress correspond with lower reported career satisfaction and an increased likelihood that the social worker is thinking about or planning to leave [14].

A mid-career respondent of South Asian Muslim descent noted: "Initially interested in aircraft, I chose to pivot to work on space systems in undergrad after seeing the devastation of the Iraq War caused by planes I had admired. But have since found it impossible to find space science jobs without MIC ties. ...I can no longer ignore the decade long daily struggle of feeling complicit in the death and destruction of people like me across the world. ...I'm likely to leave the industry. I'm an explorer to my core but I'm alienated by an industry that claims to support humanity's best instincts about seeking knowledge while being complicit in enabling some of the most destructive."

\subsection{Recommendations for Action}

Based on the initial analysis presented above, the authors have several recommendations to address the issues raised. These fall into two broad categories: research and organizational reform.

Our primary recommendation is the continuation and expansion of research to understand the extent of the impact of space science's ties to the MIC on DEIA in space science. Our initial theory building and analysis was based on a small sample of narratives from space science workers. We recommend funding collaborations between space and social science research teams to comprehensively study issues raised in this paper. Some specific hypotheses for future study, gleaned from our work, are:

- Ethical conflicts regarding space science involvement in the MIC may affect recruitment and retention of space science workers with a disproportionate impact on BIPOC, particularly those with ties to US MIC active conflict zones domestically and internationally

- Mental health problems, particularly via ethical stress, may be present in our field due to relationships with the MIC, and may be more prevalent among employees from marginalized groups

- The extent of involvement with MIC has a negative impact on the number of jobs available in the field for those with ethical concerns around MIC work 
We also recommend analyzing historical debates about these issues in the aerospace industry as well as adjacent fields, such as nuclear physics (e.g. the history of the Union of Concerned Scientists [15]).

Secondly, there are steps that space science institutions can pursue now to aid in the continued research suggested above and begin to address the conflicts and damage described by our respondents:

- Organizing workshops (similar to the NASA Ames Next Generation Exploration Conference Series) on envisioning organizational structures that address the ethical conflicts raised in this paper

- Being transparent about funding and collaborations with MIC in public materials about their work including recruitment literature

- Create a public database of space science organizations and their ties to MIC similar to transparency campaigns around fossil fuel industry ties to scientific endeavors (e.g. campaign at University of California - San Diego [16])

- Collaborate with existing groups working on these issues in the space domain such as Just Space Alliance and Open Lunar Foundation, as well as BIPOC-led organizations addressing MIC impacts on BIPOC

\subsection{References}

[1] Stockholm International Peace Research Institute, "SIPRI Arms Industry Database | SIPRI", sipri.org, 2020. [Online]. Available:

https://www.sipri.org/databases/armsindustry. [Accessed: 13- Sep- 2020].

[2] B. Glaser and A. Strauss, The discovery of grounded theory. Hawthorne, N.Y: Aldine de Gruyter, 1967.

[3] Z. Khan, E. Nesvold, R. Smith, S. Sweirsz and L. Walkowicz, "Space Science \& the Military-Industrial Complex White Paper - Community Stories - Submission Deadline June 30th Corresponding Author: Zahra Khan (zahrak@alum.mit.edu)", Google Docs, 2020. [Online]. Available: https://www.tinyurl.com/spacescienceMICwhitepaper.

[Accessed: 13- Sep- 2020].

[4] Reaching Critical Will, "Research and advocacy projects: The Aerospace Industry", Reachingcriticalwill.org, 2020. [Online]. Available:

https://www.reachingcriticalwill.org/resources/publications-and-research/researchprojects/6203-the-aerospace-industry. [Accessed: 13- Sep- 2020].

[5] MIT Lincoln Labs Beaver Works, "Research and innovation through project-based learning | Beaver Works", beaverworks.II.mit.edu, 2020. [Online]. Available:

https://beaverworks.Il.mit.edu/CMS/bw/.

[Accessed: 13- Sep- 2020].

[6] We Charge Genocide, "We Charge Genocide: Police Violence Against Chicago's Youth of Color, Shadow Report to the United Nations Committee Against Torture", report.wechargegenocide.org, 2014. [Online] Available:

http://report.wechargegenocide.org/. [Accessed: 13- Sep- 2020].

[7] T. Smith, "The General Social Surveys: GSS Project Report No. 32", National Opinion Research Center (NORC) at the University of Chicago, Chicago, 2016.

[8] American Academy of Arts \& Sciences, "The Public Face of Science in America:

Priorities for the Future", amacad.org, 2020. [Online] Available: 
https://www.amacad.org/publication/public-face-science-america-priorities-future.

[Accessed: 13- Sep- 2020].

[9] A. LaMontagne et al., "Workplace mental health: developing an integrated

intervention approach", BMC Psychiatry, vol. 14, no. 1, 2014. Available: 10.1186/1471-

244x-14-131 [Accessed 13 September 2020].

[10] A. LaMontagne, "Invited Commentary: Job Strain and Health Behaviors--

Developing a Bigger Picture", American Journal of Epidemiology, vol. 176, no. 12, pp. 1090-1094, 2012. Available: 10.1093/aje/kws337 [Accessed 13 September 2020].

[11] A. LaMontagne, T. Keegel, A. Louie and A. Ostry, "Job stress as a preventable upstream determinant of common mental disorders: A review for practitioners and policy-makers", Advances in Mental Health, vol. 9, no. 1, pp. 17-35, 2010. Available:

10.5172/jamh.9.1.17 [Accessed 13 September 2020].

[12] B. Schneider, K. Grebner, A. Schnabel, H. Hampel, K. Georgi and A. Seidler, "Impact of employment status and work-related factors on risk of completed suicide", Psychiatry Research, vol. 190, no. 2-3, pp. 265-270, 2011. Available:

10.1016/j.psychres.2011.07.037 [Accessed 13 September 2020].

[13] M. Corley, P. Minick, R. Elswick and M. Jacobs, "Nurse Moral Distress and Ethical Work Environment", Nursing Ethics, vol. 12, no. 4, pp. 381-390, 2005. Available:

10.1191/0969733005ne809oa [Accessed 13 September 2020].

[14] P. O'Donnell et al., "Predictors of Ethical Stress, Moral Action and Job Satisfaction in Health Care Social Workers", Social Work in Health Care, vol. 46, no. 3, pp. 29-51, 2008. Available: 10.1300/j010v46n03_02 [Accessed 13 September 2020].

[15] "History", Union of Concerned Scientists, 2020. [Online]. Available:

https://www.ucsusa.org/about/history. [Accessed: 13- Sep- 2020].

[16] Green New Deal at UCSD, "UC Faculty Governance formally requests transparency of fossil fuel investments from Napolitano and Chief Investment Officer Green New Deal at UCSD", Ucsdgreennewdeal.net, 2020. [Online]. Available:

https://ucsdgreennewdeal.net/index.php/2020/07/01/uc-faculty-governance-formallyrequests-transparency-of-fossil-fuel-investments-from-napolitano-and-chief-investmentofficer/. [Accessed: 13- Sep- 2020]. 